\title{
POLYMORPHISM OF CYTOCHROME P450 2A6 (CYP2A6*1 AND CYP2A6*4) AMONG JAVANESE INDONESIAN SMOKER AND NON SMOKER
}

\author{
Christine Patramurti ${ }^{1,2}$, Sugiyanto ${ }^{3 *}$, Arief Nurrochmad ${ }^{3}$, Sudibyo Martono ${ }^{4}$
}

\author{
1.Postgraduate Programe \\ Pharmaceutical Science, \\ University of Gadjah Mada, \\ 55281. Yogyakarta, \\ Indonesia \\ 2Faculty of Pharmacy, \\ University of Sanata Dharma, \\ Mrican, Tromol Pos 29, \\ Yogyakarta 55002 \\ 3.Dept. of Pharmacology and \\ Clinical Pharmacy, Faculty of \\ Pharmacy University of \\ Gadjah Mada, 55281. \\ Yogyakarta, Indonesia \\ 4.Departement of \\ Pharmaceutical Chemistry, \\ Faculty of Pharmacy, \\ University of Gadjah Mada, \\ 55281. Yogyakarta, \\ Indonesia,
}

Submitted: $10-10-2014$

Revised: 17-11-2014

Accepted: $10-12-2014$

*Corresponding author

Sugiyanto

Email :

dahlansugiyanto@yahoo.com

\begin{abstract}
Cytochrome P450 2A6 (CYP2A6) is the principal enzyme involved in the metabolic activation of tobacco-specific nitrosamines to their ultimate carcinogenic forms and metabolism of nicotine. The present study was developed to investigate the genetic polymorphism of CYP2A6 in Javanese Indonesian subjects carrying the CYP2A6*1 allele and the CYP2A6*4. The whole gene deletion of CYP2A6 (CYP2A6*4) may inhibit smokers from giving up smoking, but appears to function as a protective factor against some cancer. However, the investigation of these allele, a major functional polymorphisms common in Asian populations, have not been reported among Javanese Indonesian population. A single polymerase chain reaction-restriction fragment length polymorphism was used to resolve the genotypes into CYP2A6*1 (wild type) and CYP2A6*4 (CYP2A6del). The sample studied consisted of 100 healthy subject that consist of 50 non smokers and 50 smoker from Javanese Indonesian population. The allele frequencies of $* 1$ (wild type) and $* 4$, were 47.5 and $52.5 \%$, respectively. When the two allel were considered simultaneously, among the nonsmokers, $45 \%$ were genotyped for CYP2A6*1/*4 and 5\% were genotyped for CYP2A6*4/*4; on the other hand all of the smoker were genotyped for CYP2A6*1/*4 and there was no homozygote of wild type. Based on the data collected, it could be concluded that the polymorphism of CYP2A6 were detected in among Javanese population sample study and the allele frequencies of CYP2A6*4 were high.
\end{abstract}

Key word: Polymorphism, CYP2A6*1, CYP2A6*4, Javanese Indonesian

\section{INTRODUCTION}

The cytochrome P450 2A6 (CYP2A6) gene is expressed at a high level in liver and at lower levels in nasal mucosa and respiratory tract (Fernandez-Salguero et al., 1995). CYP2A6 plays an important role in the activation of many procarcinogens, including aflatoxin B1, $\mathrm{N}$-nitrosodiethylamine, and 1,3-butadiene and some tobacco-related nitrosamines, as well as in the clearance of some pharmaceuticals (Kushida et al., 2000; Oscarson, 2001; Raunio et al., 2008; Yoshida et al., 2002). In addition, CYP2A6 is involved in the metabolism of nicotine, the primary compound in tobacco that establishes and maintains tobacco dependence (Benowitz et al., 2011; Gullstén, 2000; Hukkanen et al., 2005; Messina et al., 1997; Oscarson, 2001).
A genetic polymorphism of CYP2A6 was recognized as one of the causes for the interindividual differences in the metabolism of nicotine (Heravi et al., 2010; Johnstone et al., 2006; Kwon et al., 2001; Lea et al., 2005; Nagano et al., 2010; Nakajima et al., 2006; Yang et al., 2001). There are 80 numbered CYP2A6 allelic variants identified to date, however, not all have been functionally characterized (www.cypalleles.ki.se/cyp2a6.htm). Among 80 CYP2A6 allelic variants, CYP2A6*4 presents a whole gene deletion (Oscarson et al., 1999), that accounts for the majority of poor metabolizer $(\mathrm{PM})$ in Asian populations (Nakajima and Yokoi, 2005; Oscarson, 2001).

The CYP2A6*4 allele is of great importance in correlation studies, for example, smoking behaviour, pre-carcinogen activation 
or drug metabolism to the CYP2A6 genotype, in particular when oriental populations are investigated (Oscarson, 2001). Subjects who are homozygotes for CYP2A $6 * 4$ are completely deficient in nicotine formation and polymorphism may inhibit smokers from giving up smoking (Ando et al., 2003; Ariyoshi et al., 2002; Fujieda et al., 2004; Minematsu et al., 2006; Rao et al., 2000). However, since the subjects lacking the CYP2A6 gene cannot activate N-nitrosamines such as NNK and N'nitrosonornicotine, which are contained in tobacco smoke as nicotine-derived carcinogens, it indicates that smokers carrying the CYP2A6*4 allele might have less risk of tobacco-related cancers (Ariyoshi et al., 2002; Fujieda et al., 2004; Liu et al., 2013; Minematsu et al., 2003; Nowell et al., 2002; Topcu et al., 2002; Wang et al., 2013).

A high frequency of CYP2A6*4 among Malaysian Malay population was reported (Yusof and Gan, 2009), but in Indonesian population the allele frequency of CYP2A6*4 have not been reported yet. The present study was developed to investigate the genetic polymorphism of CYP2A6 in Javanese Indonesian subjects carrying the CYP2A6*1 allele and the CYP2A $6 * 4$.

\section{MATERIAL AND METHODS \\ Subjects and data collection}

Individuals involved in this study had to have Javanese parents and grandparents. Subjects were healthy male volunteers, between 18 and 50 years-old, took no concurrent medications, and had no illnesses requiring investigation or treatment and have signed a statement of informed consent. This study was approved by the Ethics Committees of Medical Research Gadjah Mada University (Yogyakarta, Indonesia).

The sample population involved 100 adult subjects (50 non smokers and 50 smokers) that were recruited from students and staffs of Sanata Dharma University. The non smokers were those who had never smoked in their life. Smokers were considered current smokers if they smoked up to 1 year before the date of the interview, not currently planning to stop smoking, smoke between 1 and 30 cigarettes daily. Information was collected on the amount of cigarettes smoked per day
(CPD), the age at which the subject started smoking, the nicotine content of the cigarettes, and time to smoke the first cigarette of the day, which is generally accepted as a clinical index for nicotine dependence (Kubota et al., 2006).

\section{CYP2A6 genotyping}

Blood samples were collected from venous blood samples into EDTA containing tubes and genomic DNA was extracted by the salting-out method using Ron's Blood and Cell DNA Mini Kit (Bioron-GmbH). The genotyping of $\mathrm{CYP} 2 \mathrm{~A} 6 * 4$ was based on polymerase chain reaction (PCR)/restriction fragment length polymorphism and was performed by a previously described method (Ariyoshi et al., 2000; Muroi et al., 2012) with minor modifications. Briefly, a novel forward primer named 2A6-B6 (5'-CCT CAT CAC ACA CAA CTT CCT C-3') and a reverse primer named 2A6-UTRAS1 (5'-TGT AAA ATG GGC ATG AAC GCC C-3') were used to amplify the common regions of CYP2A $6 * 1$ and $\mathrm{CYP} 2 \mathrm{~A} 6 * 4$. The PCR reaction was perform using KAPA HiFi HotStart PCR Kit (Kapa Biosystems) that contained 1 x Kapa GC Rich HiFi Buffer (contain $2 \mathrm{mM} \mathrm{MgCl}_{2}$ ), $0.3 \mathrm{mM}$

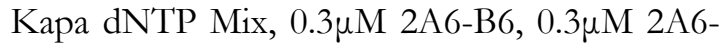
UTRAS1, 1 U Kapa HiFi HotStart DNA Polymerase, and approximately 50ng of genomic DNA in a final volume of $25 \mu \mathrm{L}$. PCR was carried out under the following conditions: initial denaturation at $95^{\circ} \mathrm{C}$ for $5 \mathrm{~min}$; followed by 30 cycles of denaturation at $98^{\circ} \mathrm{C}$ for $20 \mathrm{~s}$, annealing at $64^{\circ} \mathrm{C}$ for $15 \mathrm{~s}$ and extension at $72^{\circ} \mathrm{C}$ for $30 \mathrm{~s}$; and subsequently a final extension at $72^{\circ} \mathrm{C}$ for $5 \mathrm{~min}$. The PCR product patterns were analyzed by electrophoresis with $1 \%$ agarose gel. The PCR products consisted of 1358-bp fragments from the CYP2A6*1 allele and 1356-bp fragments from the CYP2A6*4 allele; these fragments were digested with Eco81 I (Thermo Scientific). The digestion patterns were analyzed by electrophoresis with $1 \%$ agarose gel. Fragments of 824 bp and 728 bp were derived from the CYP2A $6 * 1$ and CYP2A6*4 alleles, respectively.

\section{Data analysis}

Two CYP2A6 alleles (CYP2A6*1 (wild type allele), and $\mathrm{CYP} 2 \mathrm{~A} 6 * 4$ were identified in the Javanese Indonesian subjects used 
in the study. According to the genotypes, subjects were divided into three groups: normal metabolizers, low metabolizers and poor metabolizers. In brief, normal metabolizers were defined as having allele $* 1 / * 1$; slow metabolizers had allele $* 1 / * 4$ which was associated with $50 \%$ of the activity of normal metabolizers; and poor metabolizers had allele $* 4 / * 4$ which was associated with less than $25 \%$ of the activity of normal metabolizers (Mwenifumbo et al., 2008; Schoedel et al., 2004). The frequencies of CYP2A6 genotypes for each allele were assessed using Hardy Weinberg distribution. Differences in allele frequencies and genotype among smokers and non smokers were assessed using the chi-square test.

\section{RESULT AND DISCUSSION}

The population heterogenity in Indonesia consists of ethnic classifications, based on continental origin, racial background or physical appearance. The main aim of the study was to investigate the distribution of cytochrome P450 2A6 (CYP2A6) among Javanese Indonesian people. Two CYP2A6 alleles (CYP2A6*1 (wild type allele) and CYP2A6*4 were identified in the Javanese subjects used in the study. The selection of variant alleles for genotyping was based on functional importance and occurance frequency in Asian (Nakajima and Yokoi, 2005; Oscarson, 2001).

We examined the frequency of the variant alleles in Javanese Indonesian that consist of 50 smokers and 50 nonsmoker with a mean age of 33 years (Table I). The smokers were selected according to their smoking habits which were categorized into three levels: light smokers (CPD: 1-10), intermediate smokers (CPD: 11-20) and heavy smokers (CPD: 21-30) (Yang et al., 2001). According to B-Rao (2001), the minimum sample size in genetic polymorphism studies with two allele detected is 50. In these sample size both alleles will be detected in high probability.

In this study, the amplification of the CYP2A6*1 and CYP2A6*4 alleles were successfully carried out using polymerase chain reaction (PCR)/restriction fragment length polymorphism (Muroi et al., 2012). The primers 2A6-B6 were used to amplify exon 8 (Nunoya et al., 1999) and the primers 2A6-UTRAS1 were used to amplify regions from exon 1 to the 3 'untranslated region of the CYP2A6 gene. In this reaction, primers were specifically designed for amplification of either the CYP2A $6 * 1$ or the $\mathrm{CYP} 2 \mathrm{~A} 6 * 4$ allele, allowing for the convenient detection of heterozygous or homozygous carriers of the CYP2A $6 * 4$ allele. The CYP2A6*4 allele genotyped in this study was the CYP2A6*4A variant, which is identical to CYP2A6*4C (Ariyoshi et al., 2000; Muroi et al., 2012). The CYP2A6*4C allele is suggested to have arisen due to an unequal crossing-over event with CYP2A7 (Nunoya et al., 1999). Studies on the CYP2A6 gene have been rather problematic, because the highly (94\%) homologous CYP2A7 gene is located just $25 \mathrm{~kb}$ upstream of the CYP2A6 gene (Rautio, 2003).

In vitro DNA amplification of the CYP2A6 gene using these specific primers resulted in a 1358-bp fragments from the CYP2A6*1 allele and 1356-bp fragments from the CYP2A6*4 allele. Further, to differentiate between CYP2A6*1 allele and CYP2A6*4 allele, the PCR products were digested using Eco801 I. The 824 bp and 728 bp were derived from the CYP2A6*1 and CYP2A6*4 alleles, respectively (Ariyoshi et al., 2000; Muroi et al., 2012) (Figure 1).

A PCR product was detected in all $(100 \%)$ samples. Among 50 non smokers, 45\% were genotype for CYP2A $6 * 1 / * 4$ and $5 \%$ were genotype for CYP2A $6 * 4 / * 4$; on the other hand all of the smoker were genotype for CYP2A6*1/*4. These data suggested that the distribution of $\mathrm{CYP} 2 \mathrm{~A} 6 * 1 / * 4$ genotype frequency was not different significantly $\left(\chi^{2}=3.841 ; \mathrm{P}=0.022\right)$ between smokers and non smokers in this study population (Table II).

The allele frequencies of CYP2A $6^{*} 4$ are highly variable among races. The reported frequencies of $\mathrm{CYP} 2 \mathrm{~A} 6 * 4$ allele is $0.5 \%$ in Spaniards $(\mathrm{n}=100), 15.1 \%$ in Chinese $(\mathrm{n}=96)$ (Oscarson et al., 1999), 1,2\% in Caucasian $(\mathrm{n}=296)$ (Rao et al., 2000), $11 \%$ in Korean (Kwon et al., 2001), 20.1\% in Japanese $(\mathrm{n}=92)$ (Nakajima et al., 2001), and $16.7 \%$ in Malaysians ( $\mathrm{n}=24)$ (Yusof and Gan, 2009). Among these studies, Asian showed to have a relatively high frequency of CYP2A6*4 allele. In this study, the allele frequencies of $\mathrm{CYP} 2 \mathrm{~A} 6 * 1$, and $\mathrm{CYP} 2 \mathrm{~A} 6 * 4$ in the Javanese Indonesian $(n=100)$ were 
Table I. Demographic characteristics and CYP2A6 genotypes of subjects according to smoking status

\begin{tabular}{ccccc}
\hline \multirow{2}{*}{ Characteristics } & \multicolumn{4}{c}{ Smoking status } \\
\cline { 2 - 5 } & \multirow{2}{*}{ Non smokers } & Smokers \\
\cline { 3 - 5 } & 50 & 20 & Intermediete & Heavy \\
\hline Number of subjects & & & 17 \\
\hline Age & $33 \pm 8$ & $33.6 \pm 9.1$ & $34.94 \pm 9.56$ & $36.07 \pm 8.78$ \\
Mean \pm SD & $18-45$ & $18-45$ & $18-46$ & $22-47$ \\
Range & - & $8.15 \pm 1.17$ & $13.06 \pm 1.03$ & $22.69 \pm 0.95$ \\
Number of CPD & - & $6-10$ & $12-14$ & $21-24$ \\
Mean \pm SD & & &
\end{tabular}

$47.5 \%$ and $52.5 \%$, respectively. A high frequencies of CYP2A6*4 in the Javanese were consistent with the finding of the other results above.

In these study, no CYP2A6*1 homozygous were found both in non smokers and smokers, these data imply that there is no difference in the frequency of CYP2A $6 * 4$ alleles among smokers when compared with non-smokers. It is worth noting that the gene deletion mutation $\mathrm{CYP} 2 \mathrm{~A} 6^{*} 4$ as being homozygous, was detected in only five out of the 50 non smokers tested.

CYP2A6 deletion alleles (CYP2A6*4) are of great importance in studies to aimed at correlating smoking behaviour, pre-carcinogen activation or drug metabolism with the CYP2A6 genotype, especially in Oriental populations. A number of studies have found that smokers who inherit CYP2A6 alleles associated with slower nicotine metabolism presumably need to smoke fewer cigarettes to achieve the same pharmacological effect experienced by smokers who inherit CYP2A6 alleles associated with faster nicotine metabolism. The study by Ariyoshi et al. (2002) exhibits a tendency of the subjects with the CYP $2 \mathrm{~A} 6 * 1 \mathrm{~B} / * 1 \mathrm{~B}$ genotype to smoke a higher number of cigarettes per day (average number 20-40 cigarettes) than the subjects with the CYP2A $6 * 1 \mathrm{~A} / * 1 \mathrm{~A}$ genotype (average 20-30 cigarettes). Ando et al. (2003) found the lack of a significant impact of heterozygous CYP2A6 deletion on smoking behavior. Fujieda et al. (2004) reported that subjects carrying СYP2A6*4, CYP2A6*7, CYP2A6*9 and
CYP2A6*10 alleles smoked significantly less than subjects with the CYP2A $6 * 1 / * 1$ genotype (combining CYP2A6*1A and CYP2A6*1B). Slow metabolizers smoked fewer cigarettes per day and had an earlier age of first smoking (Schoedel et al., 2004). According to Minematsu et al. (2006), homozygous mutants and compound heterozygotes (CYP2A6*4, CYP2A6*7 and CYP2A6*9) smoked fewer cigarettes daily than heterozygotes and homozygous wild-type individuals (CYP2A6*1). CYP2A6 poor metabolizer genotypes were associated with lighter smoking, a later age of initiation and a shorter duration of smoking (Liu et al., 2011). However, these observations remain conflicting. Other studies have failed to detect an association between genetically low CYP2A6 activity and the number of cigarettes smoked. Genetic variation in CYP2A6 did not correlate with the ability to quit smoking (Kwon et al., 2001) and there is no significant difference in the smoking status was observed according to the CYP2A6 genotype (Gambier et al., 2005; Tan et al., 2001). This discrepancy may be partly explained by the different frequencies of inactive allele.

Regarding the basis for the classification of the CYP2A6 genotypes into three groups, we recently analyzed that all of the smoker were classified as slow metabolizers as having $\mathrm{CYP} 2 \mathrm{~A} 6 * 1 / * 4$ genotype (Mwenifumbo et al., 2008; Schoedel et al., 2004). The results indicate that the CYP2A6 genotype does not have any notable effect on the number of smoked cigarettes among smokers. 


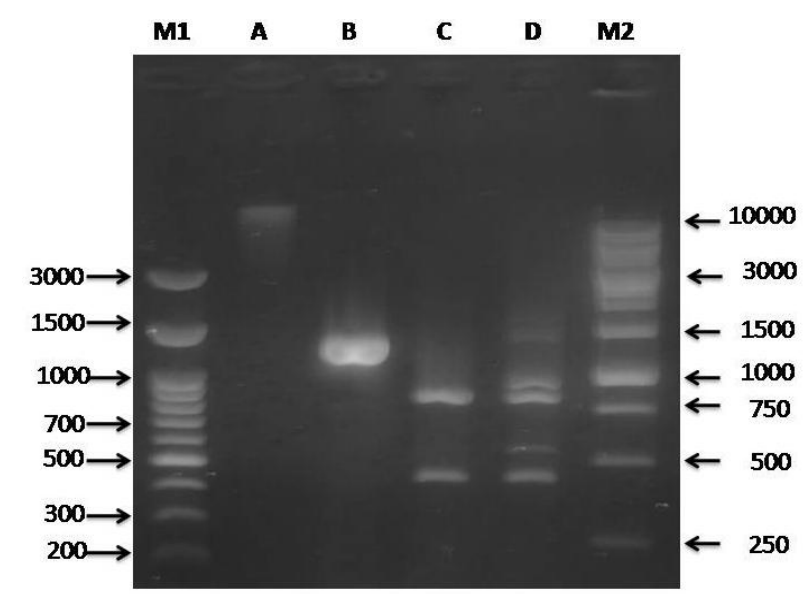

Figure 1. Electrophoregrame PCR product and Digested product identification of CYP2A6*1 and CYP2A6*4 allele. M1: Marker DNA Ladder, A: Isolated DNA, B: PCR Product (1358/1356bp), C: Digested Product (728bp) and D: Digested Product (824bp and 728bp), M2: Marker DNA ladder.

Table II. CYP2A6 genotype and allele frequencies in the Javanese Indonesian according to smoking status

\begin{tabular}{cccccc}
\hline & \multicolumn{4}{c}{ Observed Frequency } \\
\cline { 2 - 5 } Genotypes & \multicolumn{3}{c}{ Number of Subject (n=100) } & \multirow{3}{*}{ Total } \\
\cline { 2 - 5 } & Nonsmoker & \multicolumn{3}{c}{ Smoker (50) } & \\
\cline { 2 - 5 } & $\mathbf{( 5 0 )}$ & Light & Intermediate & Heavy & \\
\hline CYP2A6*1/CYP2A6*1 & $0(0)$ & $0(0)$ & $0(0)$ & $0(0)$ & $0(0)$ \\
CYP2A6*1/CYP2A6*4 & $45.0 \%(45)$ & $20.0 \%(20)$ & $17.0 \%(17)$ & $13.0 \%(13)$ & $95.0 \%(95)$ \\
CYP2A6*4/CYP2A6*4 & $5.0 \%(5)$ & $0.0 \%(0)$ & $0.0 \%(0)$ & $0.0 \%(0)$ & $5.0 \%(5)$ \\
Allele & & Number of Allele (n=200) & & \\
CYP2A6*1 & $22.5 \%(45)$ & $10.0 \%(20)$ & $8.5 \%(17 \%)$ & $6.5 \%(13)$ & $47.5 \%(95)$ \\
CYP2A6*4 & $27.5 \%(55)$ & $10.0 \%(20)$ & $8.5 \%(17 \%)$ & $6.5 \%(13)$ & $52.5 \%(105)$ \\
\hline
\end{tabular}

Futhermore we did not find any significant association between CYP2A6 gene defect and tendency to tobacco smoker among Javanese participants. These observations are consistent with previous findings that impaired function of CYP2A6 could not reduce cigarette consumption. The similar frequency of the CYP2A6*4 genotype in non smokers and smokers may be important (Table II) in understanding the essential role of CYP2A6 genotypes in smoking related diseases, because the CYP2A6*4 allele does not protect subjects from becoming habitual smokers. It is clear that CYP2A6 genetic variations are only part of the genetic basis of addiction to nicotine, smoking depends on many genetic and situational factors.
CYP2A6 plays a major role in the metabolism of nicotine and coumarin, and involveds in the clearance of certain pharmaceuticals and the activation of some tobacco-related nitrosamines (Oscarson et al., 1998; Pelkonen et al., 1999; Raunio et al., 2001). It is important to know whether the different alleles are producing active enzyme able to metabolize drugs and other toxic or carcinogenic chemicals. Daigo et al. (2002) found that when giving tegafur (an anticancer drug) to gastric cancer patients with a CYP2A6 poor metabolizer status, the patient could not produce high enough concentrations of the active metabolite to have a beneficial effect of the drug treatment. It is possible that in the future, when physicians prescribe medication to 
their patients, they need information on the patient's CYP status. Other studies reported that the frequency of the CYP2A6*4C was significantly lower in the lung cancer patients than healthy volunteers, suggesting that the subjects carrying the $\mathrm{CYP} 2 \mathrm{~A} 6 * 4 \mathrm{C}$ alleles are resistant to carcinogenesis caused by $\mathrm{N}$ nitrosamines because of the poor metabolic activation capacity (Islam et al., 2013; Kamataki et al., 2002; Muroi et al., 2012; Tan et al., 2001; Wang et al., 2013). It could be speculated that individuals who have CYP2A6*4 allele may also be less efficient at bioactivating tobacco smoke procarcinogens to carcinogens.

\section{CONCLUSION}

Based on the data collected, it could be concluded that the polymorphism of CYP2A6 were detected in among Javanese population sample study and the allele frequencies of CYP2A6*4 were high. The findings of this study also provide evidence that among these sample study are more likely to be genetically slower nicotine metabolizers. However, to evaluate the real effect of CYP2A6 gene defect on addiction to tobacco smoke, further studies that more precisely address smoking addictive behavior, tobacco consumption and current smoke intake via measurement of valid biomarkers such as CO-hemoglobin, cotinine and 3-hydroxycotinine/cotinine ratio are necessary.

\section{ACKNOWLEDGMENT}

The authors would like to appreciate for the Research Grant from Directorate General of Higher Education, Ministry of National Education Indonesia for their financial support. The results presented in this work have been taken from a Post Graduate Pharmacy Science student's thesis.

\section{REFERENCES}

Ando M., Hamajima N., Ariyoshi N., Kamataki T., Matsuo K., Ohno Y., 2003. Association of CYP2A6 gene deletion with cigarette smoking status in Japanese adults. J. Epidemiol. 13, 176-181.

Ariyoshi N., Miyamoto M., Umetsu Y., Kunitoh H., Dosaka-Akita H., Sawamura YI., Yokota J., Nemoto N., Sato K., and Kamataki T., 2002. Genetic polymorphism of CYP2A6 gene and tobacco-induced lung cancer risk in male smokers. Cancer Epidemiol. Biomark. Prev. 11, 890-894.

Ariyoshi N., Takahashi Y., Miyamoto M., Umetsu Y., Daigo S., et al., 2000. Structural characterization of a new variant of the CYP2A6 gene (CYP2A6*1B) apparently diagnosed as heterozygotes of CYP2A $6 * 1 \mathrm{~A}$ and CYP2A6*4C. Pharmacogenetics. 10, 687693.

Benowitz NL., Dains KM., Dempsey D., Wilson M., Jacob P., 2011. Racial differences in the relationship between number of cigarettes smoked and nicotine and carcinogen exposure. Nic. Tob. Res. 13, 772-783.

B-Rao C., 2001. Sample size considerations in genetic polymorphism studies. Human Heredity, 52, 191-200.

Daigo S., Takahashi Y., Fujieda M., Ariyoshi N., Yamazaki H., et al., 2002. A novel mutant allele of the CYP2A6 gene (CYP2A6*11) found in a cancer patient who showed poor metabolic phenotype towards tegafur. Pharmacogenetics. 12, 299306.

Fernandez-Salguero P., Hoffman SM., Cholerton S., Mohrenweiser H., et al., 1995. A genetic polymorphism in coumarin 7-hydroxylation: sequence of the human CYP2A genes and identification of variant CYP2A6 alleles. Am.J. Hum. Genet. 57, 651-660.

Fujieda M., Yamazaki H., Saito T., Kiyotani K., Gyamfi MA., et al., 2004. Evaluation of CYP2A6 genetic polymorphisms as determinants of smoking behavior and tobacco-related lung cancer risk in male Japanese smokers. Carcinogenesis. 25, 2451-2458.

Gambier N., Batt AM., Marie B., Pfister M., Siest G., Visvikis-Siest S., 2005. Association of $\mathrm{CYP} 2 \mathrm{~A} 6 * 1 \mathrm{~B}$ genetic variant with the amount of smoking in French adults from the Stanislas cohort. Pharmacogenomics J. 5, 271-275.

Gullstén H., 2000. Significance of Polymorphism in CYP2A6 Gene. Academic Dissertation. Department of 
Pharmacology and Toxicology Universtiy of Oulu, Oulu.

Heravi RE., Ramezani M., Behravan J., 2010. Association Between Nicotine Metabolism and CYP2A6*1 and CYP2A6*4 Genotypes in an Iranian Population. DNA Cell Biol. 29, 369-373.

Hukkanen J., Jacob PIII., Benowitz NL., 2005. Metabolism and disposition kinetics of nicotine. Pharmacol. Rev. 57, 79-115.

Islam MS., Ahmed MU., Sayeed, MSB., Maruf AA., Mostofa AGM., Hussain SMA., Kabir Y., Daly AK., Hasnat A., 2013. Lung cancer risk in relation to nicotinic acetylcholine receptor, CYP2A6 and CYP1A1 genotypes in the Bangladeshi population. Clin. Chim. Acta Int. J. Clin. Chem. 416, 11-19.

Johnstone E., Benowitz N., Cargill A., Jacob R., Hinks L., Day I., Murphy M., Walton R., 2006. Determinants of the rate of nicotine metabolism and effects on smoking behavior. Clin. Pharmacol. Ther. 80, 319-330.

Kamataki T., Fujita K., Nakayama K., Yamazaki Y., Miyamoto M., Ariyoshi N., 2002. Role of human cytochrome P450 (CYP) in the metabolic activation of nitrosamine derivatives: application of genetically engineered Salmonella expressing human CYP. Drug Metab. Rev. 34, 667-676.

Kubota T., Nakajima-Taniguchi C., Fukuda T., Funamoto, M., Maeda M., Tange E., Ueki R., Kawashima K., Hara H., Fujio Y., Azuma J., 2006. CYP2A6 polymorphisms are associated with nicotine dependence and influence withdrawal symptoms in smoking cessation. Pharmacogenomics J. 6, 115-119.

Kushida H., Fujita K., Suzuki A., Yamada M., Endo T., Nohmi T., Kamataki T., 2000. Metabolic activation of Nalkylnitrosamines in genetically engineered Salmonella typhimurium expressing CYP2E1 or CYP2A6 together with human NADPHcytochrome P450 reductase. Carcinogenesis. 21, 1227-1232.

Kwon JT., Nakajima, M., Chai S., Yom YK., Kim HK., Yamazaki H., Sohn DR., Yamamoto T., Kuroiwa Y., Yokoi T.,
2001. Nicotine metabolism and CYP2A6 allele frequencies in Koreans. Pharmacogenetics. 11, 317-323.

Lea R., Benowitz N., Green M., Fowles J., Vishvanath A., Dickson S., Lea M., Woodward A., Chambers G., Phillips, D., 2005. Ethnic differences in nicotine metabolic rate among New Zealanders. N. Z. Med. J. 118, U1773.

Liu T., David SP., Tyndale RF., Wang H., Zhou Q., Ding P., He YH., Yu XQ., Chen W., Crump C., Wen XZ., Chen WQ., 2011. Associations of CYP2A6 genotype with smoking behaviors in southern China. Addict. Abingdon Engl. 106, 985-994.

Liu T., Xie CB., Ma WJ., Chen WQ., 2013. Association between CYP2A6 genetic polymorphisms and lung cancer: a metaanalysis of case-control studies. Environ. Mol. Mutagen. 54, 133-140.

Messina ES., Tyndale RF., Sellers EM., 1997. A major role for CYP2A6 in nicotine Coxidation by human liver microsomes. $J$. Pharmacol. Exp. Ther. 282, 1608-1614.

Minematsu N., Nakamura H., Furuuchi M., Nakajima, T., Takahashi S., Tateno H., Ishizaka A., 2006. Limitation of cigarette consumption by CYP2A $6 * 4, * 7$ and $* 9$ polymorphisms. Eur. Respir. J. 27, 289292.

Minematsu N., Nakamura H., Iwata M., Tateno H., Nakajima T., Takahashi S., Fujishima S., Yamaguchi K., 2003. Association of CYP2A6 deletion polymorphism with smoking habit and development of pulmonary emphysema. Thorax. 58, 623628.

Muroi A., Kiyotani K., Fujieda M., Ishikawa H., Takeshi T., Iwano S., Yamazaki H., Kamataki T., 2012. Effect of Genetic Polymorphism of CYP2A6 on Individual Susceptibility to Colorectal Tumors in Japanese Smokers. J. Cancer Ther. 3, 207215.

Mwenifumbo JC., Al Koudsi N., Ho MK., Zhou Q., Hoffmann EB., Sellers EM., Tyndale RF., 2008. Novel and established CYP2A6 alleles impair in vivo nicotine metabolism in a population of Black African descent. Hum. Mutat. 29, 679-688. 
Nagano T., Shimizu M., Kiyotani K., Kamataki T., Takano R., Murayama N., Shono F., Yamazaki H., 2010. Biomonitoring of urinary cotinine concentrations associated with plasma levels of nicotine metabolites after daily cigarette smoking in a male Japanese population. Int. J. Environ. Res. Public. Health. 7, 2953-2964.

Nakajima, M., Fukami, T., Yamanaka, H., Higashi, E., Sakai, H., Yoshida, R., Kwon, J.-T., McLeod, H.L., and Yokoi, T., 2006. Comprehensive evaluation of variability in nicotine metabolism and CYP2A6 polymorphic alleles in four ethnic populations. Clin. Pharmacol. Ther. 80, 282-297.

Nakajima M., Kwon JT., Tanaka N., Zenta T., Yamamoto Y., Yamamoto H., Yamazaki H., Yamamoto T., Kuroiwa Y., Yokoi T., 2001. Relationship between interindividual differences in nicotine metabolism and CYP2A6 genetic polymorphism in humans. Clin. Pharmacol. Ther. 69, 72-78.

Nakajima M., Yokoi, T., 2005. Interindividual variability in nicotine metabolism: Coxidation and glucuronidation. Drug Metab. Pharmacokinet. 20, 227-235.

Nowell S., Sweeney C., Hammons G., Kadlubar FF., Lang NP., 2002. CYP2A6 activity determined by caffeine phenotyping: association with colorectal cancer risk. Cancer Epidemiol. Biomark. Prev. Publ. Am. Assoc. Cancer Res. Cosponsored Am. Soc. Prev. Oncol. 11, 377-383.

Nunoya KI., Yokoi T., Kimura K., Kainuma T., Satoh K., Kinoshita M., Kamataki T., 1999. A new CYP2A6 gene deletion responsible for the in vivo polymorphic metabolism of (+)-cis-3,5-dimethyl-2-(3pyridyl)thiazolidin-4-one hydrochloride in humans. J. Pharmacol. Exp. Ther. 289, 437-442.

Oscarson M., 2001. Genetic polymorphisms in the cytochrome P450 2A6 (CYP2A6) gene: implications for interindividual differences in nicotine metabolism. Drug Metab. Dispos. Biol. Fate Chem. 29, 91-95.

Oscarson M., Gullstén H., Rautio A., Bernal ML., Sinues B., Dahl ML., Stengård JH., Pelkonen O., Raunio H., IngelmanSundberg M., 1998. Genotyping of human cytochrome P450 2A6
(CYP2A6), a nicotine C-oxidase. FEBS Lett. 438, 201-205.

Oscarson M., McLellan RA., Gullstén H., Yue QY., Lang MA., Bernal ML., Sinues B., Hirvonen A., Raunio H., Pelkonen O., Ingelman-Sundberg M., 1999. Characterisation and PCR-based detection of a CYP2A6 gene deletion found at a high frequency in a Chinese population. FEBS Lett. 448, 105-110.

Pelkonen, O., Raunio, H., Rautio, A., and Lang, M., 1999. Xenobiotic-metabolizing enzymes and cancer risk: correspondence between genotype and phenotype. LARC Sci. Publ. 77-88.

Rao Y., Hoffmann E., Zia M., Bodin L., Zeman M., Sellers EM., Tyndale RF., 2000. Duplications and defects in the CYP2A6 gene: identification, genotyping, and in vivo effects on smoking. Mol. Pharmacol. 58, 747-755.

Raunio HC., Hakkola J., Pelkonen O., 2008. The CYP2A Subfamily, in: Cytochromes P450: Role in the Metabolism and Toxicity of Drugs and Other Xenobiotics. Royal Society of Chemistry.

Raunio H., Rautio A., Gullstén H., Pelkonen O., 2001. Polymorphisms of CYP2A6 and its practical consequences. Br. J. Clin. Pharmacol. 52, 357-363.

Rautio A., 2003. Polymorphic CYP2A6 and its clinical and toxicological significance. Pharmacogenomics J. 3, 5-7.

Schoedel KA., Hoffmann EB., Rao Y., Sellers, EM., Tyndale RF., 2004. Ethnic variation in CYP2A6 and association of genetically slow nicotine metabolism and smoking in adult Caucasians. Pharmacogenetics. 14, 615-626.

Tan W., Chen GF., Xing DY., Song CY., Kadlubar FF., Lin DX., 2001. Frequency of CYP2A6 gene deletion and its relation to risk of lung and esophageal cancer in the Chinese population. Int. J. Cancer. 95, 96-101.

Topcu Z., Chiba I., Fujieda M., Shibata T., Ariyoshi N., Yamazaki H., Sevgican F., Muthumala M., Kobayashi H., Kamataki T., 2002. CYP2A6 gene deletion reduces oral cancer risk in betel quid chewers in Sri Lanka. Carcinogenesis. 23, 595-598. 
Wang L., Zang W., Liu J., Xie D., Ji W., Pan Y., Li Z., Shen J., Shi, Y., 2013. Association of CYP2A6*4 with susceptibility of lung cancer: a meta-analysis. PloS One. 8, e59556.

Yang M., Kunugita N., Kitagawa K., Kang SH., Coles B., Kadlubar FF., Katoh T., Matsuno K., Kawamoto T., 2001. Individual differences in urinary cotinine levels in Japanese smokers: relation to genetic polymorphism of drugmetabolizing enzymes. Cancer Epidemiol.
Biomark. Prev. Publ. Am. Assoc. Cancer Res. Cosponsored Am. Soc. Prev. Oncol. 10, 589-593.

Yoshida R., Nakajima M., Watanabe Y., Kwon JT., Yokoi T., 2002. Genetic polymorphisms in human CYP2A6 gene causing impaired nicotine metabolism. Br. J. Clin. Pharmacol. 54, 511-517.

Yusof W., Gan, SH., 2009. High prevalence of CYP2A6*4 and CYP2A6*9 alleles detected among a Malaysian population. Clin. Chim. Acta Int. J. 403, 105-109. 